\title{
Protocolos de cuerpo y estilo
}

\author{
Cielo dandi. Escrituras y poéticas de estilo en América latina \\ de Juan Pablo Sutherland
}

Ed. Eterna Cadencia. Buenos Aires, 2011.

Raquel Olea

Universidad de Santiago de Chile raquelolea@vtr.net

\begin{abstract}
Cielo dandi, el reciente libro de JPS continúa el gesto de antologador e historiador iniciado por el autor en $A$ corazón abierto, en que al trabajo de selección de textos y autores, agrega el gesto político de abrir la historia literaria a lugares

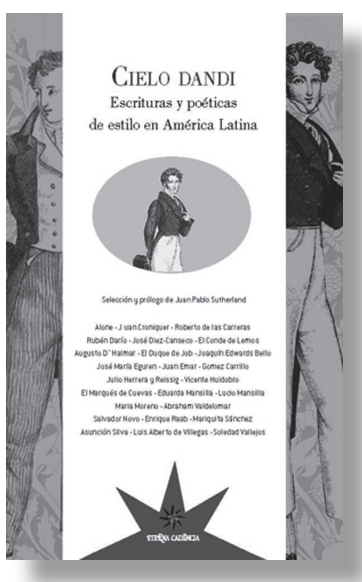
ra. Hoy podemos leer alteridades no leídas.

Si en A corazón abierto se dio lugar a una interrogación sobre las escrituras homosexuales, en la producción de significaciones de los textos, sin importar la identidad sexual de otros que los ya establecidos, ampliando las formas recorta el problema de las esde leer el canon de la literatura crituras y poéticas de estilo, en latinoamericana. Al abrir el catá- la configuración de un posible logo de obras con la incorpora- catálogo dandi latinoamericano, ción de los otros, los olvidados, o mejor de una escena dandi los réprobos, el autor realiza una en la literatura. La propuesta propuesta política de reorgani- plantea algunas reflexiones, se zación de la historia literaria. Su trata de pensar la relación entre gesto es contemporáneo y tiene estilo de autor y estilo literario. que ver con políticas de la lectu- Lo que podría leerse como una
\end{abstract}


forma de responder a la institución de los cánones y géneros literarios, de desjerarquizar la relación entre texto y autor, sin privilegio de uno sobre otro; la forma de vida de un autor, su circulación, sus relaciones y su lucimiento social serían factores desde los que emerge la obra, lo que intervendría también la lectura. Antes que centrada en la proposición de la relación arte/ vida tan propia de la concepción del escritor maldito, la figura del dandi emerge, según Sutherland -como un efecto, como la producción de un artefacto cultural altamente situado en el espacio público: un flaneur -se dice-, un paseante, un callejero, un esteta del ocio, uno que se muestra para que lo muestren y mira para ser mirado; que además escribe sobre eso, sobre sí mismo y sobre lo que lo circunda en una constelación que interroga con su actitud estética los espacios y normas de circulación de cuerpos y deseos.

La pregunta fundamental que leo en este libro tal vez sea sobre la posibilidad de hablar de dandismo desde Latinoamérica, más allá del deseo que hayan tenido estos escritores de incorporarse y/o participar del cosmopolitismo moderno; una de las lecturas que se ha hecho de la época del modernismo a la que, en parte, pertenecen los autores seleccionados.

¿Cuáles serían los gestos, intenciones y productividad del dandismo latinoamericano, más allá de una copia europeizante de lo que se ha leído como decadentismo, bohemia o romanticismo agónico?

JPS nos lleva a pensar desde acá la imagen posible de un cielo dandi como un paraíso artificial que quiere darle un lugar a lo latinoamericano en el dandismo histórico. Pero, ¿qué se trataría de configurar aquí con el signo dandi, en los autores o textos? ¿Un autor catalogado de dandi produce necesariamente literatura dandi? ¿Qué sería, si es así, un texto dandi? ¿Podríamos hablar de una literatura dandi: de géneros, estéticas escrituras? Si hubiera una literatura dandi, cual es su particularidad? Un ejemplo podría ser el texto del Conde de Camors... "Tras la cortina de terciopelo carmesí guarnecida de flecos de oro, que ornaba el marco de un balcón de la regia estancia se hallaban juntos en fría tarde invernal arrullados por las ráfagas..." (196). El fragmento da cuenta de un deseo 
lujoso y lujurioso alimentado tal vez en lecturas que abrían las puertas a la fantasía de lo inalcanzable, lo imposible....

Recordemos que visto desde una perspectiva europea, los latinoamericanos que circulaban en Europa, principalmente en el París de la época, están al borde de una figura algo patética, una frontera entre el arribista y el allegado, un parvenu, un petit maitre (petimetre), un rastacueros, también un sujeto sin colocación, un fabulador que alcanza el cielo con mentiras, como dice J. E. Bello sobre el Marques de Cuevas: “Comprenderá el lector escéptico por qué es Jorge Cuevas la noticia más importante de este 3 de septiembre de 1953. El joven sin porvenir de 1908 y 1918, ha hecho vociferar al pueblo francés, en Biarritz, y las prensas crujen para estampar su nombre en diversas regiones de esa $\mathrm{Eu}$ ropa donde llegó, con una maletita y cuatro cartas, hace 30 años, Cuevas, es decir ese símbolo, ese fenómeno que para nosotros seguirá siendo Cuevas es para los europeos el hijo de un noble español y de una dama danesa, nacida por casualidad en Chile, y lleva el título del Marqués de Piedra blanca de Guana" (199).
El dandi, que según Baudelaire, es una figura heroica que resiste al proceso de uniformidad propio del capitalismo burgués, es también uno de sus productos.

El dandi ha sido pensado como un símbolo del individuo frente a la masa, uno que construye su "yo" desde la apariencia y las prácticas de la elegancia, de actitudes gestos y discursos de efectismo social. El dandi puede entenderse como una producción continua de efectos sociales; su voluntad es el cultivo de la diferencia y la ambigüedad artificiosa y dada al puro placer, una resistencia a los modos de exigencia de la vida burguesa dentro de las mismas formas que la vida burguesa otorga a quienes están fuera de la lógica de la producción en una sociedad industrializada que fabrica sujetos seriados; el dandi europeo proclama la estética como su fin único. En ese contexto pienso que los dandis latinoamericanos vendrían a constituir una "zona de contacto" -utilizo la imagen acuñada por M. L. Pratt para establecer los signos con que los viajeros y viajeras del S. XIX construyeron la alteridad- digo, un cuerpo en tránsito en el que se rozan y se posan signos de acá y de allá; un espacio de travesía y circulación de desmantelamientos 
y desmanes de género, de clase, y de "habitus", un locus donde se integran y cruzan diversas manías personales con la productividad y el ocio, con el deseo y el desprecio por la riqueza y donde el juego se da en el misterio de lo que no se tiene y lo que no se es. En los notables retratos sociales que constituye la literatura de Balzac, por ejemplo abunda la figura del arribista, el dandi: ninguno que lo haya conocido podrá olvidar a Rastignac y su deseo de advenir a formas sociales que le han sido esquivas.

Entre los dandis latinoamericanos parece haber habido de todo: aristócratas viajeros y viajeros pobres; el viaje parece haber sido un requisito ineludible en el recorrido del dandi; así lo señala María Moreno al referirse al escritor argentino -Arturito-, antologado por JPS, “Arturo Álvarez nació en 1921 en un departamento de la calle Esmeralda. En 1924 lo llevaron a París y dice que todavía lo recuerda".

Rubén Darío, vino de Matagalpa a Valparaíso, acercándose al centro, una ciudad inglesada, según Edwards Bello, de ahí siguió a Buenos Aires finalmente desembarcó en París con un sobretodo comprado en Valparaíso y que luego llegó a manos de
Paul Verlaine (118). No sé si Edwards Bello es dandi o no, pero si es cronista del dandismo latinoamericano en París; Amado Nervo escribe crónicas de la vida Madrileña y Alberto de Villegas da cuenta de la moda del privat -bar a borde del transatlántico Berengaria; un dandi latinoamericano es, o al menos aspira a ser cosmopolita. Tiene que ser viajado, quizás por eso la crónica sea uno de los géneros propios del dandismo latinoamericano, género que como sabemos busca realizar el registro, la anotación de lo que sucede, tal vez para facilitar al dandismo criollo informaciones sobre la moda dandi a los que vienen, establecer una guía; otro de los rasgos que se observa en un aspirante a dandi es su capacidad de transformación, el dandi es camaleónico: "Le consideró como otro caso de metamorfosis de criollos en París. El aire nuevo, el clima, la alimentación tonificante les transformaba o les revelaban dándoles su verdadera personalidad. París les hacía ser lo que eran. El Dueñas apocado de Santiago no era el Dueñas sátiro y cínico de Paris", dice E. Bello.

Pero también la vida de París los situaba en la verdadera dimensión de su ser periférico, así cuando el guatemalteco Enri- 
que Gómez Carrillo declara que "dos cosas me hacen desear que la muerte no venga pronto y que son sagradas, serían abrazar a Verlaine y darle la mano a Huysmans"; escribe que "al encontrarme en la estancia reducida y modesta en que el gran novelista francés recibe a sus amigos, lo primero que hice fue hablarle del pobre gran poeta americano que con tanto ardor le admiró durante su existencia y que murió pensando en él ¿Julián del Casal? ... ¿un poeta?

Naturalmente Huysmans no le conocía, ¿Quien conoce en Francia a los que escriben versos en América? aclara Gómez Carrillo (143). La visita, la carta de presentación eran también requisitos que abrían puertas a los aspirantes a dandis y por supuesto la elegancia, el estar a la moda; condiciones a las que el dandi no podía renunciar, "La elegancia es un don espiritual. Es la propia manera del espíritu, como lo sería el estilo en un escritor", dice José María Eguren.

El dandismo europeo, se constituyó en torno a las figuras emblemáticas de Brummel, Baudelaire y $\mathrm{O}$. Wilde, tres formas muy distintas de ser dandi y de ser escritor. Pensarlos hace significativo pensar hoy la continuidad del dandismo, aunque ya no podría serlo con el aura que alguna vez tuvo. Después de la muerte del autor y su resurrección transformado en producto mediático, donde las nociones de performance y celebrity darían la medida de una verdad que dura poco, el dandi contemporáneo -si es que pudiera nombrárselo así-, pienso que sería una figura fuertemente asociada a la producción de modas de marca y mercados de imagen y obra, a la metáfora de la profusión de ritos publicitarios que dominan el presente, donde una imagen se superpone rápidamente a otra en una suerte de vacío permanente que continúa la tradición de un ansioso reconocimiento del centro.

El dandismo histórico por el contrario parece haber sido un derroche de narcisismo, una compulsión del Yo, una fragancia de melancolía y exhibicionismo, en la que los latinoamericanos participaron con el deseo de ser parte de eso que se llamó mal del siglo (mal de siècle).

Los autores antologados en Cielo dandi, en su mayoría escriben en la vuelta del siglo XIX, hasta la mitad del XX aproximadamente, excepto María Moreno 
y Soledad Vallejos autoras contemporáneas que escriben sobre dandis.

La pregunta si es que hay mujeres dandis que el autor plantea, en una estrategia de corrección política, creo que no podría responderse con ese tipo de autoras o al menos no en la relación de sus escrituras con alguna de las antologadas, demasiado femeninas, a mi juicio. La pose femenina que el dandi ha hecho suya no queda bien a las mujeres, si el dandismo moviliza identidades fijas, el gesto de una mujer dandi creo que iría hacia el lado de la libertad de las amarras de su sexo, hacia una pose de autonomía y libertad, por eso me parece dudoso pensar a Teresa Wilms con su excesiva feminidad como una mujer dandi, tampoco veo a Eduarda Mansilla, como una dandi, su lugar de esposa de diplomático, que escribe su Diario de viaje demasiado deslumbrada por lo que ve en Francia y luego en E.E. U.U. y que ella quisiera que se imitara para formar la gran nación argentina. Me parece que a Eduarda Mansilla le falta el brillo de la libertad erótica que circunda el dandismo. Teresa Wilms, por su parte, a pesar de su extraordinaria belleza, muere de ausencias y de costos patriarcales por sus experiencias libertarias.

La pregunta de JPS amerita una construcción, más que una trasposición de los rasgos del dandi -eminentemente varóna la figura de una mujer. Pensar una mujer dandi es pensar antes que otra cosa una sujeto deseante, resistente a la enmarcación de un retrato femenino dependiente de los códigos burgueses. Una mezcla quizás de apropiaciones masculinas a la producción de una alteridad femenina, de una otredad, una ambigüedad propia de la experimentalidad y de nuevas experiencias corporales.

En Latinoamérica, pienso en la necesidad de una exploración distante de la figura de la musa romántica o la figuración de la entrega a la pasión y el deseo del varón que llevó a tantas mujeres a un final trágico.

Quizás las llamadas mujeres de la Rive gauche que circularon en la primera mitad del Siglo XX en el París de la época, entre las que destacaron Gertrude Stein, Anais Nin, Colette, Djuna Barnes, -entre otras- podrían ser un ejemplo de dandismo femenino; ellas también traspasaron fronteras, hicieron arte, escribieron y vivieron con estilo, amaron a los hombres, se amaron entre ellas y oficiaron de sacer- 
dotisas; actuaron en el afuera de los órdenes del capitalismo burgués que las quería femeninas y sumisas, pero ninguna de ellas está referida en el cielo visitado por los latinoamericanos que volvieron a sus países hechos unos dandis europeizados.

Quizás sea Carlos Monsivais, finalmente la voz que autoriza la existencia del dandismo latinoamericano. Él y Silvia Molloy con sus miradas agudas y críticas podrían responder mi pregunta inicial sobre los gestos, productividad e identidad del dandismo latinoamericano.

Dice JPS citando a Monsivais, "Novo no es un travesti, no es alguien que disimule sus inclinaciones, es en rigor una pose, la semblanza animada que denuncia la proclividad a través de los desfiguros alucinados y divertidos"... ... "Es demasiado pero es único".

Único y tránsfuga el sujeto que Cielo Dandi pone en escena se escribe en el punto de cruce de una no pertenencia, de la constitución del cuerpo como ejercicio de una fuga a ninguna parte. Eso, creo podría ser lo que nos haría hacer pensar en su continuidad.

Si antes de leer Cielo Dandi no sabíamos si se podía hablar de dandismo en Latinoamérica, y más aún si hubo mujeres dandi, ahora tenemos en este libro la provocación necesaria para iniciar el debate. 
